\title{
Stress - strain Experimental Study on Cement Composite Soil Constitutive Model
}

\author{
Chen Ronglin, Zeng Zhixing \\ College of Civil Engineering, Huaqiao University, 361021, China
}

Keywords: Cement Soil; Stress-Strain Curve; Constitutive Model

\begin{abstract}
Cement soil and cement-soil pile are widely used in engineering practice, especially in soft soil foundation treatment, foundation pit maintenance, slope reinforcement, grouting and water blocking works, it has played a very important role. Due to the wide range of cement soil application, cement admixture is also widely used in cement soil, in order to adapt to the actual project in the early strength, enhance, the impermeability and other needs. However, due to regional differences in soil quality, adulterated cement soil engineering properties are also very different, often in engineering practice, they are will be difficult to pile, the strength is not enough and other issues appear, making the treatment costs grow greatly. In this paper, the unconfined compressive strength tests of cement soil with different cement contents, different original water and different curing ages were carried out. The main factors influencing the strength of common cement soil were found by the experiment. The results show that, with the increase of cement content, the strength of cement soil increases linearly. With the increase of soil original water content, the strength of cement soil first increases and then decreases, presenting a parabolic change. With the increase of curing age, the strength of cement soil increases, which shows a good linear relationship between the two, so that the constitutive model of the soil under uniaxial compression is obtained
\end{abstract}

\section{Introduction}

Cement soil is based on soil, cement, water (in some specific projects need to be based on the addition of external admixture) as the main raw material, through a certain ratio of mixing, by compaction, curing the formation of a mixture Cement soil is a hardened material with special engineering properties. Since the 1980s, the application of cement soil has been widely promoted in our country and satisfactory results have been achieved. Especially in soft ground treatment, channel lining, embankment seepage control played a good role. In the basic project, commonly used cement soil reinforcement of silt, silt soil and foundation bearing capacity of less than 120kpa of clay and silt soil. With the development of the global economy, the transportation demand is expanding constantly, the level of urbanization is gradually accelerating, the development of cities and roads shows a trend of large-scale acceleration, the construction and maintenance of roads and slope protection are rapidly increasing, and urban construction projects are also growing rapidly at the same time. Therefore, A lot of building materials. In the general civil engineering construction of the total cost, with material-related costs accounted for more than $50 \%$, but in the actual project, the choice of materials, the use of a great impact on the cost of construction, cement and soil as a building material can be drawn on the spot Can achieve the purpose of reducing project cost. China's economy has been growing at an annual rate of 9\% per year on average in the world, with cities and roads being built faster than other countries. It is pointed out in the literature that the mileage of China's expressways has doubled in recent ten years. At the same time, the construction of the city is correspondingly doubled. Regardless of road construction or urban construction involves a lot of earth and stone works, and cement soil can effectively replace the sand stone material and part of the concrete, to achieve the purpose of saving investment.

As a new type of construction material, cement soil is also widely used in water conservancy projects. There are 800 million agricultural population now in our country and agriculture plays a decisive role in the national economic construction. China's arable land accounts for the world's cultivated land $4 \%$ of the plot, but feed the world's one fifth of the population. In agricultural 
development, due to rainfall in our country are uneven in space and time, making irrigation occupy an important component. At present, the effective utilization of water transport channels in China is less than 60\%, much lower than $70 \%-80 \%$ in developed countries. If China's water delivery efficiency increased by $10 \%$, it is equivalent to build a South-North Water Diversion Project. Since the 70s of last century, cement soil began to develop in our country. Cement soil has been used in the lining of the river that I have passed in the South, and the effect is good, saving a lot of concrete and saving investment. The use of cement-soil materials to build channel lining, can speed up agricultural construction.

Cement soil mainly in the form of cement soil mixing pile due to excellent engineering properties make it in road engineering, coastal engineering and various types of infrastructure projects are widely used, with the wide application of cement soil, cement soil constitutive relations. On the basis of previous research results, the main research results of cement soil constitutive model can be summarized into three kinds: elastoplastic constitutive model, damage constitutive model and elastoplastic damage constitutive model. Based on the experimental results, the elasto-plastic constitutive model of nano-sized cemented soil under yield condition is established based on the elasto-plastic theory. The theoretical basis is provided for the finite element analysis, stress analysis and settlement calculation [8]. Based on the critical state theory, the stress ratio parameters are introduced, and the plastic strain increment is analyzed by regression analysis to get the plastic potential of cement-soil. The plastic-plastic constitutive model of cement-soil material is established by using the rules of strain hardening and flow of plastic body [9]. By using the simulation ability of BP network instead of the traditional algorithm, the constitutive relation of soil-cement under erosive environment is obtained. At the same time, a new method is provided for the constitutive relationship of geomaterials under the influence of many factors. After applying the damage mechanics theory to geomaterials, the damage constitutive relation and damage evolution equation of cement-soil are established based on the concept of continuity damage mechanics. The damage evolution equation and damage constitutive model are established indoors Test verification [10].

\section{Test Materials and Methods}

\subsection{Soil Samples}

The test soil samples for the newly accumulated fully disturbed clay, loose soil, soil uniformity, removal of the surface of the sample about $5 \mathrm{~cm}$ surface soil, the soil samples were air-dried, crushed with a wooden stick, over $2 \mathrm{~mm}$ sieve, and in accordance with the "soil test Method standard "(GB / T50123-2002), the specific gravity test, water content and boundary water content test, compaction test and particle analysis test are carried out on the soil samples. Table 1 and Table 2 show the physical performance indexes and Chemical composition, particle distribution using laser particle size analyzer determination, the composition of the results shown in Table 3 and Figure 1

Tab.1 Main performance of soil

\begin{tabular}{ccccc}
\hline \hline Liquid Limit/ \% & Plastic Limit\% & Plastic Index & Maximum Dry Density & Optimal moisture content \\
\hline 33.5 & 21.5 & 12 & 2.05 & 9.99 \\
\hline \hline
\end{tabular}

Tab.2 The chemical elements of the soil samples

\begin{tabular}{ccccccccccc}
\hline \hline Element & $\mathrm{Na}$ & $\mathrm{K}$ & $\mathrm{Ca}$ & $\mathrm{Fe}$ & $\mathrm{Si}$ & $\mathrm{Al}$ & $\mathrm{Cl}$ & $\mathrm{Mg}$ & $\mathrm{O}$ & Totals \\
\hline Total mass $/ \%$ & 1.40 & 0.89 & 2.91 & 10.37 & 16.71 & 8.13 & 0.54 & 4.53 & 54.52 & 100.0 \\
$\begin{array}{c}\text { Atomic } \\
\text { content } / \%\end{array}$ & 1.24 & 0.48 & 1.46 & 3.84 & 12.26 & 6.21 & 0.31 & 3.86 & 70.34 & 100.0 \\
\hline \hline
\end{tabular}

Tab.3 Laser particles size analysis of soil

\begin{tabular}{ccccccccccc}
\hline \hline Item & D3 & D6 & D10 & D16 & D25 & D75 & D84 & D90 & D97 & D98 \\
\hline Soil /um & 4.87 & 6.35 & 8.30 & 12.09 & 19.82 & 112.84 & 147.73 & 183.34 & 274.21 & 304.99 \\
\hline \hline
\end{tabular}




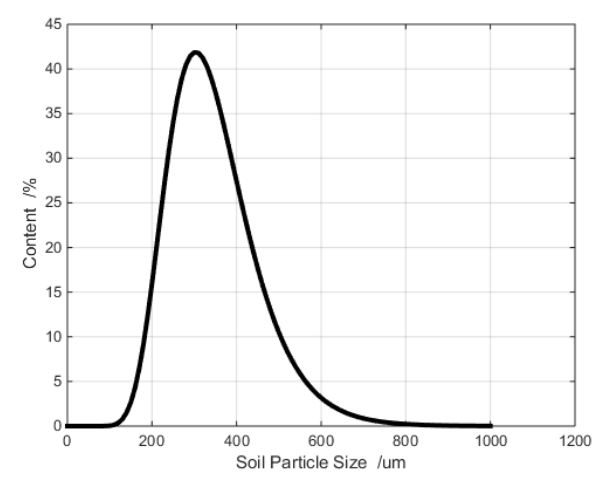

Fig.1 The particle size curve of soil

\subsection{Material properties of test cement}

Mengxi P. O42.5 ordinary Portland cement mineral composition and the main chemical composition in Table 4, Table 5, Table 6 gives particle distribution.

Tab.4 Main performance of P. O42.5 Portland cement

\begin{tabular}{cccccc}
\hline \hline Component & $\mathrm{C}_{2} \mathrm{~S}$ & $\mathrm{C}_{3} \mathrm{~S}$ & $\mathrm{C}_{4} \mathrm{AF}$ & $\mathrm{C}_{3} \mathrm{~A}$ & $\mathrm{f}-\mathrm{CaO}$ \\
\hline$\omega / \%$ & 22.09 & 55.68 & 16.77 & 5.14 & 0.32 \\
\hline \hline
\end{tabular}

Tab.5 Main performance of P. O42.5 Portland cement

\begin{tabular}{cccccc}
\hline \hline Component & $\mathrm{SiO}_{2}$ & $\mathrm{Al}_{2} \mathrm{O}_{3}$ & $\mathrm{CaO}$ & $\mathrm{MgO}$ & $\mathrm{SO}_{3}$ \\
\hline$\omega / \%$ & 22.13 & 5.19 & 63.92 & 1.09 & 2.16 \\
\hline \hline
\end{tabular}

Tab.6 Laser particles size analysis of cement

\begin{tabular}{ccccccccccc}
\hline \hline Item & D3 & D6 & D10 & D16 & D25 & D75 & D84 & D90 & D97 & D98 \\
\hline Cement /um & 5.03 & 6.56 & 8.44 & 11.57 & 17.15 & 69.38 & 92.10 & 116.10 & 176.95 & 198.12 \\
\hline \hline
\end{tabular}

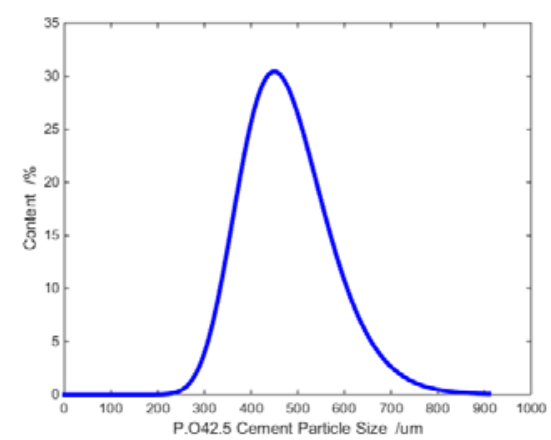

Fig.2 The particle size curve of P.O42.5

\subsection{Test Method}

In this paper, the unconfined compressive strength is taken as the evaluation index of the effect of pumice stone and other factors on the modification effect of cement soil. The unconfined compressive strength test is carried out by using the strain controlled triaxial apparatus (TSZ-6A) produced by Nanjing Soil Instrument Factory. When the sample is applied to the upper and lower ends of a layer of petrolatum, the sample placed in the next pressure plate, start the motor, the pressure plate and the sample just in contact, adjust the dynamometer and displacement meter so that the reading zero, Adjust the strain rate of $3 \%$ per minute, the use of computer automatically collected stress-strain data, after the test, remove the sample description of the damaged shape.

SEM test (scanning electron microscope) has been widely used in metallurgy, biology, materials science (metal materials, non-metallic materials, nanomaterials), medical, semiconductor materials and devices, geological prospecting, gem identification, industrial product quality identification and production Process control and other fields. Although the cement composite soil is composed of 
cement and soil material and external admixture mixed by a certain proportion, the mixture material is still dominated by soil material. Therefore, the microstructure of cement composite soil is studied, you can learn from soil microstructure research methods. The microstructural features of natural engineering soils were originally proposed by Terzaghi and Casagrande. In the late 1960s, transmission electron microscopy (TEM) and scanning electron microscopy (SEM) have been greatly developed, and the advent of this technique has provided powerful tools for studying the microstructure characteristics of materials. The S-3400N Scanning Electron Microscope used in this article was Hitachi's S-3400N Scanning Electron Microscope, a versatile instrument with superior performance. The instrument uses tungsten filament, magnification can reach 300,000 times.

\section{Cement composite soil stress-strain nonlinear constitutive relationship}

Cement soil is based on cement and soil mixed with the main admixture, soil and cement hydrates after a certain period of time after the hairA series of chemical reactions and the formation of a complex multi-phase system. Contains a large number of random distribution of micro-pores and micro-cracks and other initial defects, with uneven. In general, the properties of the composing materials as well as the various conditions and external environmental factors in the curing and using process all affect the mechanical properties of the cement soil in varying degrees, which makes the cement soil have complex and changeable strength and deformation characteristics. Therefore, the constitutive relationship of pumice cement composite soil can not simply follow the constitutive relation of general soil. It is necessary to analyze the uniaxial and triaxial test results to obtain the constitutive model which accords with the characteristics of pumice cement composite soil.
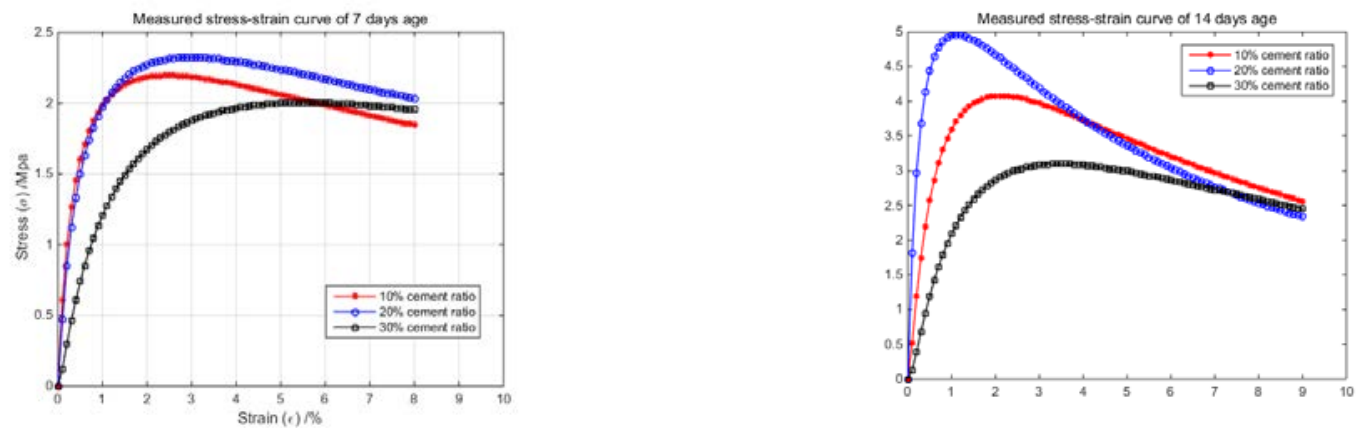

a) The measured stress-strain curve of 7 days

b) The measured stress-strain curve of 14 days

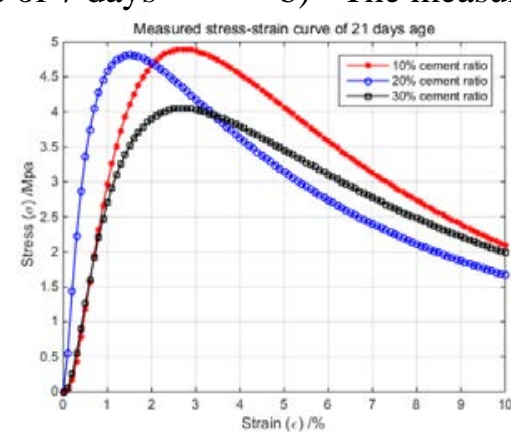

c) The measured stress-strain curve of 21 days

Fig.3 The measured stress-strain curve of different age

Uniaxial compressive strength is the material of the most basic and important performance, pumice cement composite soil in the uniaxial compression. The stress-strain relationship in the state fully reflects the deformation characteristics and the failure process of each stress stage. The required mechanical properties index values: peak strength, peak strain, elastic limit, residual strength, elastic modulus and so on. In order to better understand the mechanical properties of pumice cement composite soil, this paper cement content of $16 \%$ under the premise of different pumice powder content of different ages of cement composite soil samples unconfined compressive strength tests. Test results are shown in Figure 3. 
Through the observation of the measured stress-strain curve, it is found that the stress-strain curve of pumice cement composite soil is similar to the stress-strain curve of ordinary cement soil. According to the unconfined compressive strength test results, the typical and complete stress strain curve characteristics of pumice cement composite soil.

\section{Stress-strain curve can be divided into the following three stages}

The first stage: OA section, the initial straight line of stress-strain curve, in the initial stage of compressive test of cement soil specimen, With the increase of stress, the stress-strain curve of cement soil has an approximate linear relationship. The particles in each phase of the sample are affected. Compression molding, the particles did not occur damage, deformation of particles in the elastic deformation range, cement soil appears hardening.

The second stage: $\mathrm{AB}$ section, the stress-strain curve of the nonlinear rise, close to the peak stress, the curve deviate from the straight line, the strain increases obviously with the increase of stress, and reaches the peak value; from the point $A$, the soil of the sample gradually undergoes damage until the strength of the soil of the sample B reaches its peak, the composite soil structure is completely damaged, The particle structure is damaged, and the particle gap is continuously compressed. At this time, the compaction effect of the composite soil is stronger than the structural damage, and the deformation of the composite soil particle can not be recovered, Plastic deformation, micro-cracks appear inside the sample, macroscopically, the stress increases slowly with the increase of strain until it reaches the peak value, and the internal cracks show obvious micro-cracks on the sample surface.

The third stage: BC section, the non-linear decline of the stress-strain curve, that is, the postdestruction phase, should. When the force reaches the peak value, the cement soil softens and the stress attenuates rapidly when the strain increases not so much. After that, the curve gradually decreases and gradually reaches the residual strength value, ie point $\mathrm{C}$, and when the stress reaches its peak, the composite soil sample Cracks expand, extend, and join together to form macroscopical diagonal cracks along the weakest planes, and gradually penetrate the full cross-section as strain increases to form a damaged zone. Cracks in other parts of the specimen are no longer developed.

\section{Conclusions}

In this paper, aiming at the typical silty clay in the western part of Inner Mongolia, the strength and deformation characteristics of cement soil under the condition of adding no admixture were studied through the indoor experiment, using abundant pumice mineral resources. As a comparative basis of further pumice cement composite soil, a pumice cement composite soil material for silty clay in the western part of Inner Mongolia was prepared based on the study, and the best compounding ratio was put forward. The uniaxial compression test, triaxial compression test and microstructure test of pumice cement composite soil were carried out. The interaction between pumice cement composite material and soil, water and cement slurry was analyzed. Based on this. The curing mechanism of pumice cement composite soil was discussed. Through the uniaxial compression test of pumice cement composite soil and the result analysis, the stress-strain curve of pumice cement composite soil under uniaxial compression was summarized. On the basis of this, a Popovics model is applied to establish a nonlinear elastic-plastic constitutive model of pumice cement composite soil under uniaxial conditions. The model is simple and the parameters can be easily calculated directly or indirectly from the test results. The compressive strength of pumice cement composite soil shows an exponential change with the increase of curing age. The greater the age, the higher the strength. The strength of the pumice cement composite soil of 60 days age is about 1.6 times of the strength of 21 days.

\section{Acknowledgements}

This work was financially supported by the Experimental Teaching Reform Fund of Huaqiao 
University (Nos. 66661507, 66661625), the Natural Science Foundation of Fujian Province, China (2017J01095).

\section{References}

[1] Kasama K, Ochiai H, Yasufuku N. On the stress-strain behaviour of lightly cemented clay based on an extended critical state concept [J]. Soils and Foundations, 2000, 40(5): 37-47.

[2] Frantziskonis G, Desai C S. Constitutive model with strain softening [J]. International Journal of Solids and Structures, 1987, 23(6): 733-750.

[3] Nguyen L D, Fatahi B, Khabbaz H. A constitutive model for cemented clays capturing cementation degradation [J]. International Journal of Plasticity, 2014, 56: 1-18.

[4] Cristelo N, Cunha V M C F, Gomes A T, et al. Influence of fibre reinforcement on the postcracking behaviour of a cement-stabilised sandy-clay subjected to indirect tensile stress [J]. Construction and Building Materials, 2017, 138: 163-173.

[5] Pan Y, Liu Y, Xiao H, et al. Effect of spatial variability on short-and long-term behaviour of axially-loaded cement-admixed marine clay column [J]. Computers and Geotechnics, 2017.

[6] Yan R, Wei C. Constitutive Model for Gas Hydrate-Bearing Soils Considering Hydrate Occurrence Habits [J]. International Journal of Geomechanics, 2017, 17(8): 04017032.

[7] Tengattini A, Das A, Nguyen G D, et al. A thermomechanical constitutive model for cemented granular materials with quantifiable internal variables. Part I-Theory [J]. Journal of the Mechanics and Physics of Solids, 2014, 70: 281-296.

[8] Lin J S, Seol Y, Choi J H. An SMP critical state model for methane hydrate-bearing sands [J]. International Journal for Numerical and Analytical Methods in Geomechanics, 2015, 39(9): 969987.

[9] Zhang Y, Wang Y, Zhao N, et al. Experimental and Stress-Strain Equation Investigation on Compressive Strength of Raw and Modified Soil in Loess Plateau [J]. Advances in Materials Science and Engineering, 2016, 2016.

[10] Huang M, Liu X, Zhang N, et al. Calculation of foundation pit deformation caused by deep excavation considering influence of loading and unloading[J]. Journal of Central South University, 2017, 24(9): 2164-2171. 